\title{
Stagnation Point Flow of Williamson Nanofluid towards a Permeable Stretching/Shrinking Sheet with a Partial Slip
}

\author{
Ansab Azam Khan ${ }^{1}$, Khairy Zaimi ${ }^{2,}$, Teh Yuan Ying $^{1}$ \\ 1 School of Quantitative Sciences, UUM College of Arts \& Sciences, Universiti Utara Malaysia, UUM Sintok, Kedah Darul Aman, Malaysia \\ 2 Institute of Engineering Mathematics, Universiti Malaysia Perlis, Pauh Putra Main Campus, Arau, Perlis, Malaysia
}

\section{ABSTRACT}

\section{Article history:}

Received 19 April 2020

Received in revised form 17 June 2020

Accepted 23 June 2020

Available online 29 June 2020

\section{Keywords:}

Stagnation point; Williamson nanofluid; stretching/shrinking; suction; partial slip
The Williamson stagnation nanofluid flow over a stretching/shrinking surface with active and passive control are numerically studied. The main focus of the present study is to investigate the impacts of partial slip and suction at the boundary on the velocity, temperature, and nanoparticle volume fraction profiles and heat transfer characteristics. It is crucial to analyze the fluid flow and heat transfer problems with the inclusion of partial slip and suction effects due to an extensive variety of applications in the industry. The governing partial differential equations are reduced to a set of coupled nonlinear ordinary differential equation systems using nondimensional variables and then it is solved using the boundary value problem solver (bvp4c) in MATLAB. Results show that both velocity and nanoparticle volume fraction increase as the suction parameter increases while the temperature acts in the opposite manner. The magnitude of the reduced skin friction coefficient, the reduced Nusselt number and the reduced Sherwood number are notably increased for the first solution with the increasing suction parameter. It is seen that the nanofluid velocity increases as the partial slip parameter increases whereas the temperature and nanoparticle volume fraction of the nanofluid are decreased. As partial slip parameter enhanced, the reduced skin friction coefficient has decreased while the magnitude of both the local Nusselt number and the local Sherwood number are increasing. Dual solutions exist up to a certain range of the stretching/shrinking parameter in the shrinking flow region. The critical values of stretching/shrinking parameter increases with the increasing in suction and partial slip effect strength suggest that both parameter widens the range of dual solutions exist. Physically, the increment of the suction and slip effects has delayed the boundary layer separation. The first solution is found to be stable and physically applicable but the second solution is not based on the literature for the similar problem presented by researchers.

Copyright @ 2020 PENERBIT AKADEMIA BARU - All rights reserved

\footnotetext{
* Corresponding author.

E-mail address: khairy@unimap.edu.my (Khairy Zaimi)
} 


\section{Introduction}

The nanofluid has brought a revolutionary change in the field of fluid dynamics. These are types of modern fluids that include a based fluid and nano-particles. The term "nanofluid" was first coined by Choi [1] by suspending different nanoparticles into base fluids. It was reported that nanofluid has much better thermal properties than their base fluids. Additionally, nanofluid plays a key role to meet the cooling rate requirements with high thermal conductivity.

Over the last few years, many researchers have investigated the attribute of nanofluid and its heat transfer enhancement capability. Researchers employed nano materials to improve the efficiency of heat transfer fluids. One of the popular nanofluid model was introduced by Buongiorno [2]. He found that the absolute velocity of nano-particles was the resultant of the velocity of the base fluid and slip velocity of the nano-particles. He reported the seven slip mechanisms i.e. thermophoresis, fluid drainage, magnus effects, inertia, gravity, diffusiophoresis and Brownian diffusion. At the end, he concluded that the Brownian diffusion and thermophoresis are the main slip mechanisms. Since the pioneering work by Buongiorno [2], the study of flow of a nanofluid in different kinds of aspects and boundary conditions generate much interest among researchers. For example, Wakif et al., [3] applied the Buongiorno nanofluid model to study the thermal radiation and surface effects on the thermo-magneto-hydrodynamic stability of alumina-copper oxide hybrid nanofluids. Effects of viscous dissipation and magnetic field on fluid flow and heat transfer in a nanofluid has been analyzed by Sheri and Thumma [4], Thumma et al., [5], and Rout et al., [6]. Khan et al., [7] investigated the heat transfer performance of nanofluid in the presence of non-linear radiation. They examined the velocity slip and magnetic field effects on the nanofluid flow. They found that the heat transfer rate decreases as the power-law increases. Ali et al., [8] solved the heat and mass transfer mechanism for Carreau nanofluid flow due to a radially stretching/shrinking sheet. One significant from their study is the heat and mass transfer rates are raised by higher Weissenberg number for the first solution while the opposite trend for the second solution. Recently, Hamid et al., [9] simulated the fluid flow over a past a continuously moving thin needle immersed in a nanofluid by means of bvp4c collocation formula. They performed stability analysis to examine which solution stable and physically realizable. Different from other studies, Dero et al., [10] successfully obtained triple solutions for the problem of MHD micropolar nanofluid boundary layer flows over an exponentially stretching/shrinking sheet with radiation and suction effect using the Buongiorno nanofluid model by employing shooting method.

There are several other non-Newtonian fluid models, for example pseudoplastic fluids and Casson fluids. In heat transfer applications, Casson fluids are widely used in the processing of chocolate, foams, syrups, nail, toffee, and many other foodstuffs (see Ramachandra Prasad et al., [11]). Recently, Alkasasbeh [12] examined the steady laminar MHD natural convection flow suspended micropolar Casson fluid over a solid sphere by using the Keller-box method. However, in nonNewtonian fluids, the most commonly found fluids are pseudoplastic fluids. The flow of layers of pseudoplastic fluids is of great interest because of its wide range of applications in a sector such as the extrusion of polymer sheets, emulsion-coated sheets such as high molecular weight photographic films, solutions and melts weight of polymers, etc (Nadem et al., [13]). Williamson [14] analyzed the flow of pseudoplastic materials. He proposed a model to describe the flow of pseudoplastic fluids and experimentally verified the results. Pseudo-plastic fluids get better results when both the minimum and maximum effective viscosities are considered in the Willaimson fluid model. Nadeem et al., [13] were the first who investigated the two-dimensional boundary layer equation for the flow of the Williamson fluid past a stretching sheet. The problem is solved analytically with the help of the Homotopy analysis method (HAM). Nadeem and Hussain [15] analyzed the nanoparticle effect on the 
boundary layer flow of the Williamson fluid over a stretching surface. The governing non-linear equations are solved analytically with the help of the homotopy analysis method (HAM). Halim et al., [16] were the first to solve Williamson's nanofluid flow fields involving active and passive solvents regulating the normal mass flow in the flow signal. The expression of passive control on nanoparticles was previously proposed by Kuznetsov and Nield [17] to investigate the passive control of the normal mass flux on the flow characteristics towards a stretching surface. Most recently, Hamid et al., [18] analyzed the physical properties of Williamson fluid flow due to a stretching/shrinking surface. They have obtained multiple solutions for the flow fields and also found that the range of dual solutions exist expand with unsteadiness parameter.

Recently, many researchers investigated the aspect of heat transfer and flow problems with suction because of the numerous industrial applications. It was reported that the suction or injection plays an important role in aerodynamics and space science for example to control the fluid flow on the surface of the subsonic aircraft (Uwanta \& Hamza [19]). Suction or injection (blowing) of a fluid through the bounding surface can significantly change the flow field. In general, suction tends to increase the skin friction, whereas injection acts in the opposite manner. The effect of suction on MHD natural convective flow of nanofluid over a stationary and moving inclined porous plate by considering temperature and concentration gradients has been investigated by Thumma et al., [20].

Another physical effect to be considered in this study is the partial slip effect. It is known that the slip-flow condition in a Newtonian fluid over a linearly stretching sheet was first introduced by Andersson [21]. No-slip condition is one of the main ideas in developing the Navier-Stokes theory. However, in some non-Newtonian fluids, the no-slip condition is found to be inadequate. This is because of some polymer melt often gives microscopic wall slip and has a controlling influence by a nonlinear and monotone relation between the slip velocity and the traction. Slip impacts can happen at the boundary of pipes, walls, curved surfaces etc (Prasannakumara et al., [22]). There are certain cases, for example, particulate fluids and rarefied gases can occur slip between the boundary and the fluid (see Shidlovskiy [23], Yoshimura \& Prudhomme [24]. Thus, this present study has been motivated by the fact that partial slip effect has many applications for example the cleaning of artificial heart valves and inside cavities (Alblawi et al., [25]). Mahian et al., [26] stated that the partial slip effect has great applications in many industrial developments of the boundaries of pipes, walls or curved surfaces. The study of slip, viscous dissipation and Joule heating effects on magnetohydrodynamic Jeffery in a nanofluid has been conducted by Thumma and Mishra [27]. Thumma et al., [28], Bég et al., [29], and Thumma and Mishra [30] investigated the effect of heat/sink on flow and heat transfer in a nanofluid over a non-linear inclined stretching/shrinking sheet, from an oscillating inclined porous plate with variable temperature, and with convective conditions past a stretching sheet, respectively. Since no attempt has been made to examine the hybrid effects of suction and partial slip effects on a steady stagnation point flow of Williamson nanofluid towards a linearly stretching/shrinking sheet with both active and passive controls on the wall mass flux, this present study is conducted.

Motivated from the above-mentioned studies, the objective of the present study is to analyze the effects of partial slip and suction on Williamson stagnation point flow over a stretching/shrinking sheet with active and passive control in nanofluid. The effects suction and partial slip on velocity, temperature, concentration, skin friction, local Nusselt number and local Sherwood number are also thoroughly examined and presented in graphs and tables. This present study is basically the extension of the work done by Halim et al., [16]. Different from that investigated by Halim et al., [16], we consider partial slip and suction in a nanofluid with active and passive controls on the wall mass flux. Comparisons with previous results are presented and found in good agreement. In practical, the studies of the stagnation-point flow and heat transfer past a stretching/shrinking sheet in the 
presence of partial slip and suction effects are very significant and useful especially in many industrial manufacturing processes. Even though various kinds of research on the stagnation-point fluid flow have been considered, there are still limited published articles identified on the partial slip and suction impacts. We believe that the present numerical results are new and have not been published elsewhere.

\section{Methodology}

Consider the steady two-dimensional boundary layer flow of an incompressible Williamson nanofluid past a horizontal linearly stretching/shrinking sheet with the linear velocity $u_{w}(x)=c x$, where $c$ is a constant and $x$ is the coordinate measured along the stretching/shrinking sheet, as shown in Figure 1 . The flow takes place at $y>0$, where $y$ is the coordinate measured normal to the stretching/shrinking sheet.

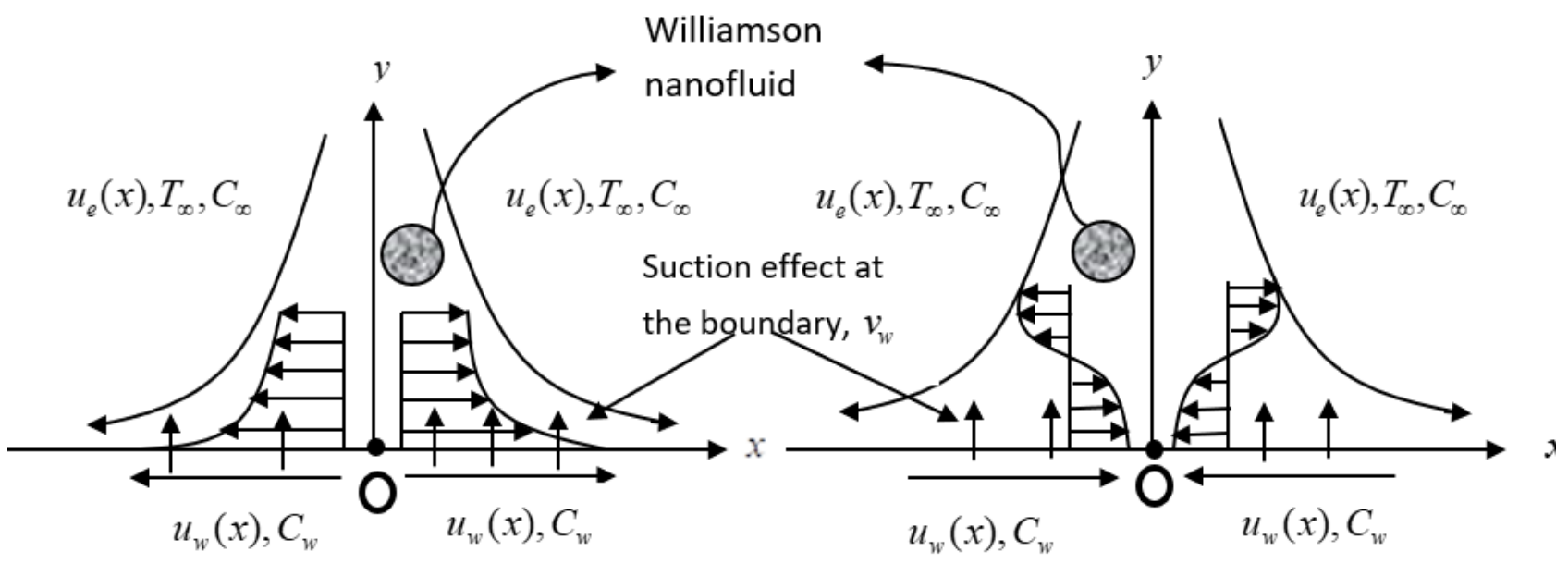

(a)

(b)

Fig. 1. Physical model of present study (a) Stretching sheet; (b) Shrinking sheet

It is assumed that at the stretching/shrinking sheet, the temperature $T$ and the nanoparticle volume fraction $C$ take constant values $T_{w}$ and $C_{w}$, respectively. The ambient temperature and concentration, attained as $y$ tending to infinity are denoted by $T_{\infty}$ and $C_{\infty}$, respectively while the ambient fluid is moving with a velocity $u_{e}(x)=a x$, where $a$ is positive constant. The nanoparticle volume fraction for passively controlled mass flux is defined separately by the temperature gradient resulting in zero nanoparticles normal flux. Under the above assumptions, the basic steady conservation of mass, momentum, thermal energy and nanoparticles equations for Williamson nanofluids can be written in Cartesian coordinates $x$ and $y$ as confirmed by Nadem et al., [13], Nadeem and Hussain [15], and Halim et al., [16].

$$
\begin{aligned}
& \frac{\partial u}{\partial x}+\frac{\partial v}{\partial y}=0 \\
& u \frac{\partial u}{\partial x}+v \frac{\partial u}{\partial y}=\frac{d u_{e}}{d x}+v \frac{\partial^{2} u}{\partial y^{2}}+\sqrt{2} \Gamma_{0} \frac{\partial u}{\partial y} \frac{\partial^{2} u}{\partial y^{2}}
\end{aligned}
$$




$$
\begin{aligned}
& u \frac{\partial T}{\partial x}+v \frac{\partial T}{\partial y}=\alpha \frac{\partial^{2} T}{\partial y^{2}}+\frac{\rho_{p} c_{p}}{\rho c} D_{B}\left(\frac{\partial C}{\partial y} \frac{\partial T}{\partial y}\right)+\frac{\rho_{p} c_{p}}{\rho c} \frac{D_{T}}{T_{\infty}}\left(\frac{\partial T}{\partial y}\right)^{2} \\
& u \frac{\partial C}{\partial x}+v \frac{\partial C}{\partial y}=D_{B}\left(\frac{\partial^{2} C}{\partial y^{2}}\right)+\frac{D_{T}}{T_{\infty}}\left(\frac{\partial^{2} T}{\partial y^{2}}\right)
\end{aligned}
$$

where $u$ and $v$ are the velocity components in the $x$ and $y$ directions, respectively, $v$ is the kinematic viscosity, $\Gamma_{0}=\frac{\Gamma}{x}>0(x \neq 0)$ is a time constant, $\alpha$ is the thermal diffusivity, $\rho c$ and $\rho_{p} c_{p}$ are heat capacities of nanofluid and nanoparticles respectively, $D_{B}$ is the Brownian diffusion coefficient and $D_{T}$ is the thermophoretic diffusion coefficient. The nanoparticle volume fraction at the surface is controlled passively by the temperature gradient resulting in zero nanoparticles normal flux.

The new boundary conditions for the flow are given as (see Halim et al., [16]):

$u=\varepsilon u_{w}(x)+U_{\text {slip }}, \quad v=v_{w}, \quad T=T_{w}, \quad$ at $y=0$,

$D_{B} \frac{\partial C}{\partial y}+\frac{D_{T}}{T_{\infty}} \frac{\partial T}{\partial y}=0$ (Passive control of $\left.\phi\right), C=C_{w}($ Active control of $\phi)$ at $y=0$,

$u=u_{e}(x)=a x, \quad T=T_{\infty}, \quad C=C_{\infty}, \quad$ as $y \rightarrow \infty$.

Here, $\varepsilon$ is the stretching/shrinking parameter with $\varepsilon>0$ for stretching case, $\varepsilon<0$ for the shrinking case, and $\varepsilon=\mathrm{O}$ for the static sheet, respectively, $v_{w}$ is the constant mass flux velocity with $v_{w}>0$ for suction and $v_{w}<0$ for injection. Furthermore, it is assumed that $U_{\text {slip }}$ is the slip velocity at the sheet, which is given by Fang et al., [31].

$U_{\text {slip }}=A \frac{\partial u}{\partial y}$

where $A$ is the dimensional slip coefficient.

The governing equations in Eqs. (1) - 4) can be transformed to a set of coupled nonlinear ordinary differential equations by introducing the following non-dimensional variables (see Halim et al., [13]).

$\eta=y \sqrt{\frac{c}{v}}, \quad \psi=\sqrt{c v} x f(\eta), \quad \theta=\frac{T-T_{\infty}}{T_{w}-T_{\infty}}$,

$\phi(\eta)=\frac{C-C_{\infty}}{C_{\infty}}($ for passive control of $\phi)$,

$\phi(\eta)=\frac{C-C_{\infty}}{C_{w}-C_{\infty}}($ for active control of $\phi)$, 
where $\psi$ is the stream function which satisfies Eq. (1)

$u=\frac{\partial \psi}{\partial y}=c x f^{\prime}(\eta) \quad$ and $\quad v=-\frac{\partial \psi}{\partial x}=-\sqrt{c v} f(\eta)$

By substituting Eqs. (9)-(12) into Eqs. (2)-(4), the following coupled nonlinear ordinary differential equations will be obtained

$f^{\prime \prime \prime}-\left(f^{\prime}\right)^{2}+f f^{\prime \prime}+r^{2}+\lambda f^{\prime \prime} f^{\prime \prime \prime}=0$

$\theta^{\prime \prime}+\operatorname{Pr} f \theta^{\prime}+\frac{N_{c}}{L e} \theta^{\prime} \phi^{\prime}+\frac{N_{c}}{L e N_{b t}}\left(\theta^{\prime}\right)^{2}=0$

$\phi^{\prime \prime}+S_{c} f \phi^{\prime}+\frac{1}{N_{b t}} \theta^{\prime \prime}=0$

The corresponding boundary conditions in Eqs. (5)-(7) become

$f(0)=\gamma, \quad f^{\prime}(0)=\varepsilon+\delta f^{\prime \prime}(0), \quad \theta(0)=1$,

$N_{c} \phi^{\prime}(0)+\frac{N_{c}}{N_{b t}} \theta^{\prime}(0)=0$ (Passive control of $\left.\phi\right), \phi(0)=1$ (Active control of $\left.\phi\right)$,

$f^{\prime}(\infty)=r, \quad \theta(\infty)=0, \quad \phi(\infty)=0$,

where primes denote the differentiation with respect to $\eta$. Here $r=a / c$ is the stagnation parameter, $\operatorname{Pr}=v / \alpha$ is the Prandtl number, $L e=\alpha / D_{B}$ is the Lewis number, $S c=v / D_{B}$ is the Schmidt number, $\delta=A \sqrt{c / v}$ denotes the slip parameter and $\gamma=v_{w} /-(c v)^{1 / 2}$ is the suction/injection parameter where $\gamma>0$ corresponds to suction and $\gamma<0$ for injection. The following non dimensional parameters are introduced by Nadeem and Hussain [15], and Halim et al., [16].

$\lambda=\Gamma \sqrt{\frac{2 c^{3}}{v}}, \quad N_{c}=\frac{\rho_{p} c_{p}}{\rho c}\left(C_{w}-C_{\infty}\right), \quad N_{b t}=\frac{D_{B} T_{\infty}\left(C_{w}-C_{\infty}\right)}{D_{T}\left(T_{w}-T_{\infty}\right)}$

Here, $\lambda$ is the non-Newtonian Williamson parameter, $N_{c}$ is the heat capacity ratio between nanoparticle heat capacity and nanofluid heat capacity while $N_{b t}$ is the diffusivity ratio between Brownian diffusivity and thermophoretic diffusivity. It is important to note that we redefined the Williamson parameter $\lambda$ by introducing the term $\Gamma_{0}=\frac{\Gamma}{x}>0$ to eliminate $x$ (see Halim et al., [16]).

The physical quantities of interest are the reduced skin friction coefficient, $C f_{x}$, the reduced Nusselt number, $N u_{x}$ and the reduced Sherwood number, $S h_{x}$ which can be defined as (see Halim et al., [16]). 


$$
C f_{x}=\frac{\tau}{\rho u_{w}^{2}(x)}, \quad N u_{x}=\frac{q_{w} x}{\alpha\left(T_{w}-T_{\infty}\right)}, \quad S h_{x}=\frac{q_{m} x}{D_{B}\left(C_{w}-C_{\infty}\right)},
$$

where the wall shear stress $\tau_{w}$, wall heat flux $q_{w}$ and the wall mass flux $q_{m}$ are given by (see Halim et al., [16]).

$$
\tau_{w}=\mu\left(\frac{\partial u}{\partial y}+\frac{\Gamma_{0}}{\sqrt{2}}\left[\frac{\partial u}{\partial y}\right]^{2}\right)_{y=0}, q_{w}=-\alpha\left(\frac{\partial T}{\partial y}\right)_{y=0}, \quad q_{m}=-D_{B}\left(\frac{\partial C}{\partial y}\right)_{y=0}
$$

By using Eqs. (9)-(11), (20) and (21), we obtain

$$
C f_{x} \operatorname{Re}_{x}^{1 / 2}=f^{\prime \prime}(0)+\frac{\lambda}{2} f^{\prime \prime}(0)^{2}, N u_{x} \operatorname{Re}_{x}^{-1 / 2}=-\theta^{\prime}(0), \quad S h_{x} \operatorname{Re}_{x}^{1 / 2}=-\phi^{\prime}(0),
$$

where $\operatorname{Re}_{x}=u_{w}(x) x / v$ is the local Reynolds number.

\section{Numerical Method: Bvp4c Solver}

The Williamson stagnation nanofluid flow and heat transfer over a stretching/shrinking sheet with inclusion suction and partial slip is investigated using appropriate governing equations. The governing PDEs in Eqs. (2)-(4) are reduced to a set of coupled nonlinear ODEs in Eqs. (13)-(15) by means of non-dimensional variables and then solved using the boundary value problem bvp4c solver in MATLAB. The purpose of reducing ODEs is to make it simpler in finding numerical solutions. In this section, we will discuss in detail the implementation of the bvp4c for the present problem.

It was reported by Hale [32] that the development and implementation of the bvp4c solver has been founded by Kierzenka and Shampine [33]. They developed the bvp4c solver to solve the boundary layer problem for a coupled nonlinear ordinary differential equation in easier technique. The bvp4c solver routine is a finite difference code that employs three order Lobatto IIla formula which provides a fourth-order numerical solution.

The first and second solutions were obtained after solving the coupled nonlinear ordinary differential equations in Eqs. (13)-(15) subject to boundary conditions in Eqs. (16)-(18). Dual solutions obtained by setting different initial guess or different values of boundary layer thicknesses $\eta_{\max }$ while the velocity, temperature and nanoparticle volume fraction profiles satisfy the infinity boundary conditions in Eq. (18) asymptotically but with different shapes.

STEP 1: Introduce new variables for the following coupled nonlinear ODES in Eqs. (13)-(15):

$$
\begin{aligned}
& y(1)=f, y(2)=f^{\prime}, y(3)=f^{\prime \prime}, \\
& y(4)=\theta, y(5)=\theta^{\prime}, \\
& y(6)=\phi, y(7)=\phi^{\prime} .
\end{aligned}
$$

STEP 2: Write the new variables Eq. (23) into first order system of equations: 


$$
\begin{aligned}
& f^{\prime}=y(2), \\
& f^{\prime \prime}=y(3) \\
& f^{\prime \prime \prime}=\frac{(y(2))^{2}-y(1) y(3)-r^{2}}{1+\lambda y(3)} \\
& \theta^{\prime}=y(5), \\
& \theta^{\prime \prime}=-\operatorname{Pr} y(1) y(5)-\left(N_{c} / L e\right) y(5) y(7)-\left(N_{c} / \operatorname{LeN}_{b t}\right)(y(5))^{2}, \\
& \phi^{\prime}=y(7), \\
& \phi^{\prime \prime}=-S c y(1) y(7)+\left(1 / N_{b t}\right)\left[-\operatorname{Pr} y(1) y(5)-\left(N_{c} / L e\right) y(5) y(7)-\left(N_{c} / \operatorname{LeN}_{b t}\right)(y(5))^{2}\right] .
\end{aligned}
$$

STEP 3: Transform the boundary conditions in Eqs. (16)-(18) according to new variables introduced:

$$
\begin{aligned}
& y a(1)=\gamma, y a(2)=\varepsilon+\delta y a(3), y a(4)=1, \\
& N_{c} y a(7)+\frac{N_{c}}{N_{b t}} y a(5)=0 \text { (Passive control), } y a(6)=1 \text { (Active control), } \\
& y b(2)=r, y b(4)=0, y b(6)=0 .
\end{aligned}
$$

Here, the subscript $a$ represents the position on the sheet, that is $\eta=0$ and subscript $b$ represent the condition far from the sheet, for example $\eta=10$.

STEP 4: Write first order system of equations in Eq. (24) with boundary conditions in Eq. (25) in MATLAB software using bvp4c solver with two different guessing values to obtain dual solutions. Using the bvp4c solver, providing an initial guess for the first solution is easy since the solution will converge to the first solution even for poor guesses. This contrary to the initial guesses for the second solution.

\section{Results and Discussion}

The coupled nonlinear ordinary differential equations in Eqs. (13) - (15) subject to boundary conditions in Eqs. (16)-(18) are solved using the bvp4c solver in MATLAB software. The code is developed based on the finite difference method and is used to solve boundary value problems for ordinary differential equations by the collocation method (Halim et al., [13]). In the present study, the parameter values used are fixed as follows: $\operatorname{Pr}=10, N_{b t}=2, N_{c}=0.5, L e=4, \lambda=0.2, S c=2$ and $r=1$. To ensure the accuracy of the present results, comparison has been made with the available published results of Halim et al., [16] in the absence of the suction and slip effects as tabulated in Tables 1 and 2. The comparisons are found to be in good agreement, and thus we are confident that the present numerical results are correct and accurate. It was established by Merkin [34], Weidman et al., [35], Harris et al., [36] and Adnan et al., [37] that for various problems, the common ordinary differential equations generally reported the existence of multiple solutions, whereby the upper branch solution is stable and the lower branch solutions are not stable. Hence, we expect this finding hold to the present study and the process of validating the stability of solutions is not repeated here. 


\section{Table 1}

Results comparison for $C f_{x} \operatorname{Re}_{x}^{1 / 2}$ and $N u_{x} \mathrm{Re}_{x}^{-1 / 2}$ for both active and passive control with different values of $r$ when $\operatorname{Pr}=10, N_{b t}=2, N_{c}=0.5, L e=4, \lambda=0.2, S c=2$ and $\varepsilon=1$ in the absence of suction $(\gamma=0)$ and slip effect $(\delta=0)$.

\begin{tabular}{lclllll}
\hline & $\begin{array}{l}C f_{x} \mathrm{Re}_{x}^{1 / 2} \\
\text { Halim et al., [16] }\end{array}$ & Present results & $\begin{array}{l}\mathrm{Nu} \mathrm{Re}_{x}^{-1 / 2} \\
\text { Halim et al., [16] } \\
\text { Active }\end{array}$ & Present results & $\begin{array}{l}\text { Halim et al., [16] } \\
\text { Passive }\end{array}$ & Present results \\
\hline 0.2 & -0.885587 & -0.885587 & 2.223107 & 2.223107 & 2.316252 & 2.316251 \\
0.3 & - & -0.821908 & - & 2.240288 & - & 2.335781 \\
0.5 & -0.650677 & -0.650676 & 2.282267 & 2.282267 & 2.382625 & 2.382625 \\
0.7 & - & - & -0.426639 & 2.330306 & - & 2.435468 \\
1.0 & 0.000000 & 0.000000 & 2.407227 & 2.407226 & 2.519242 & 2.519242 \\
1.2 & 0.341642 & 0.341641 & - & 2.459335 & 2.575648 & 2.575648 \\
1.4 & - & 0.727524 & - & 2.511044 & - & 2.631444 \\
1.5 & 0.936789 & 0.936788 & 2.536589 & 2.536588 & 2.658957 & 2.658956 \\
1.6 & - & 1.156825 & - & 2.561871 & - & 2.686159 \\
\hline
\end{tabular}

Numerical solutions for the skin friction coefficient $C f_{x} \operatorname{Re}_{x}^{1 / 2}$, the reduced Nusselt number $N u_{x} \mathrm{Re}_{x}^{-1 / 2}$ and the reduced Sherwood number $S h_{x} \mathrm{Re}_{x}^{-1 / 2}$ for several parameters are tabulated for the passive control of mass transfer in Tables 3 and 4. Following Thumma et al., [20], we used a suction parameter values between $[0,2]$ in Table 3 where $\gamma=0$ indicates no suction effect. Also, following the work done by Sharma et al., [38], the partial slip parameter used must be non-negative values. Thus, the partial slip parameter used in the present study between $[0.5,3]$ as tabulated in Table 4. Table 3 shows the values of $C f_{x} \operatorname{Re}_{x}^{1 / 2}, N u_{x} \operatorname{Re}_{x}^{-1 / 2}$ and $S h_{x} \operatorname{Re}_{x}^{-1 / 2}$ for passive control with different values of $\gamma$ when $\operatorname{Pr}=10, N_{b t}=2, N_{c}=0.5, L e=4, \lambda=0.2, S c=2, \delta=1, \quad r=1$ and $\varepsilon=-2$ (shrinking sheet). From Table 3, we notice that the increasing values of suction parameter $\gamma$ are likely to increase the values of $C f_{x} \operatorname{Re}_{x}^{1 / 2}, N u_{x} \operatorname{Re}_{x}^{-1 / 2}$ and $\left|S h_{x} \operatorname{Re}_{x}^{-1 / 2}\right|$ for the first solution, while the opposite behavior is shown for the second solution. However, the values of $C f_{x} \operatorname{Re}_{x}^{1 / 2}$ decrease for the second solution. Table 4 shows the values of $C f_{x} \operatorname{Re}_{x}^{1 / 2}, N u_{x} \operatorname{Re}_{x}^{-1 / 2}$ and $S h_{x} \operatorname{Re}_{x}^{-1 / 2}$ for different values of $\delta$ for fixed parameters: $\operatorname{Pr}=10, N_{b t}=2, N_{c}=0.5, L e=4, \lambda=0.2, S c=2, r=1, \gamma=0.5$ and $\varepsilon=-2$ (shrinking sheet) in the passive control condition. It is notified that from Table 4 the dual solution exists with the first and second solutions, and the values of $N u_{x} \operatorname{Re}_{x}^{-1 / 2}$ and $\left|S h_{x} \operatorname{Re}_{x}^{-1 / 2}\right|$ increase with the increasing slip parameter $\delta$ for the first solution. Conversely, the values of $C f_{x} \operatorname{Re}_{x}^{1 / 2}$ decrease as parameter $\delta$ increases for the first solution.

Figures 2-4 show the effects of suction parameter $\gamma$ towards the velocity, temperature and nanoparticle volume fraction profiles for passive control when $\operatorname{Pr}=10, N_{b t}=2, N_{c}=0.5, L e=4$, $\lambda=0.2, S c=2, r=1, \delta=1$ and $\varepsilon=-2$ (shrinking). It is observed that the velocity and nanoparticle volume fraction increase as $\gamma$ increases, while the temperature reacts in the opposite manner for the first solution. As depicted in Figure 2, with the increasing suction strength in flow, as the external heat velocity increases, heat is dispersed faster around it, reducing the temperature of the fluid (see Figure 3). Moreover, the momentum boundary layer thickness is also decreasing and in turn the velocity gradient at the surface has increased as illustrated in Figure 2. From Figure 3, the thermal boundary layer thickness and surface temperature are also decreased. As consequence, the temperature gradient at the surface is increasing. 


\section{Table 2}

Results comparison for $S h_{x} \operatorname{Re}_{x}^{-1 / 2}$ for both active and passive control with different values of $r$ when $\operatorname{Pr}=10$, $N_{b t}=2, N_{c}=0.5, L e=4, \lambda=0.2, S c=2$ and $\varepsilon=1$ in the absence of suction $(\gamma=0)$ and slip effect $(\delta=0)$

\begin{tabular}{|c|c|c|c|c|}
\hline$r$ & $\begin{array}{l}\mathrm{Sh}_{x} \mathrm{Re}_{x}^{-1 / 2} \\
\text { Halim et al., [16] } \\
\text { Active }\end{array}$ & Present results & $\begin{array}{l}\text { Halim et al., [16] } \\
\text { Passive }\end{array}$ & Present results \\
\hline 0.2 & 0.11880 & 0.118880 & -1.158126 & -1.158125 \\
\hline 0.3 & - & 0.144955 & - & -1.167890 \\
\hline 0.5 & 0.196667 & 0.196666 & -1.191313 & -1.191312 \\
\hline 0.7 & - & 0.245265 & - & -1.217734 \\
\hline 1.0 & 0.311215 & 0.311214 & -1.259621 & -1.259621 \\
\hline 1.2 & - & 0.350948 & -1.287824 & -1.287824 \\
\hline 1.4 & - & 0.387772 & - & -1.315722 \\
\hline 1.5 & 0.405215 & 0.405214 & -1.329478 & -1.329478 \\
\hline 1.6 & - & 0.422068 & - & -1.343079 \\
\hline
\end{tabular}

\section{Table 3}

The values of $C f_{x} \operatorname{Re}_{x}^{1 / 2}, N u_{x} \operatorname{Re}_{x}^{-1 / 2}$ and $S h_{x} \mathrm{Re}_{x}^{-1 / 2}$ for passive control with different values of $\gamma$ when $\operatorname{Pr}=10, N_{b t}=2, N_{c}=0.5, L e=4, \lambda=0.2, S c=2, r=1, \varepsilon=-2$ and $\delta=1$

\begin{tabular}{llll}
\hline$\gamma$ & $C f_{x} \mathrm{Re}_{x}^{1 / 2}$ & $N u_{x} \mathrm{Re}_{x}^{-1 / 2}$ & $S h_{x} \mathrm{Re}_{x}^{-1 / 2}$ \\
\hline 0 & 1.575097287 & 0.303031445 & -0.151507226 \\
& $(0.835478581)$ & $(0.000000023)$ & $(-0.000000012)$ \\
0.3 & 1.819832429 & 2.780826834 & -1.390413417 \\
& $(0.650826081)$ & $(0.00000009)$ & $(-0.000000004)$ \\
0.5 & 1.942836993 & 4.840158604 & -2.420079302 \\
& $(0.558498556)$ & $(0.00000003)$ & $(-0.000000015)$ \\
0.8 & 2.096478604 & 7.921538187 & -3.960769093 \\
& $(0.435597378)$ & $(0.00000858)$ & $(-0.000000429)$ \\
1.0 & 2.184623620 & 9.953386623 & -4.976693312 \\
& $(0.357019219)$ & $(0.000016063)$ & $(-0.000008031)$ \\
1.5 & 2.370331950 & 14.98597889 & -7.492989445 \\
& $(0.154079963)$ & $(0.075949089)$ & $(-0.037974544)$ \\
\hline
\end{tabular}

() dual solution

\section{Table 4}

The values of $C f_{x} \operatorname{Re}_{x}^{1 / 2}, N u_{x} \mathrm{Re}_{x}^{-1 / 2}$ and $S h_{x} \mathrm{Re}_{x}^{-1 / 2}$ for passive control with different values of $\delta$ when $\operatorname{Pr}=10, N_{b t}=2, N_{c}=0.5, L e=4, \lambda=0.2, S c=2, r=1, \varepsilon=-2$ and $\gamma=0.5$

\begin{tabular}{llll}
\hline$\delta$ & $C f_{x} \mathrm{Re}_{x}^{1 / 2}$ & $N u_{x} \mathrm{Re}_{x}^{-1 / 2}$ & $S h_{x} \mathrm{Re}_{x}^{-1 / 2}$ \\
\hline \multirow{2}{*}{0.5} & 2.090585631 & 2.787418707 & -1.383709354 \\
& $(1.110190642)$ & $(0.001698732)$ & $(-0.000849366)$ \\
1 & 1.942836993 & 4.840158604 & -2.420079302 \\
& $(0.558498556)$ & $(0.0000003)$ & $(-0.000000015)$ \\
1.5 & 1.545344892 & 5.356379321 & -2.678189660 \\
& $(0.392237104)$ & $(0)$ & $(0)$ \\
2 & 1.255073481 & 5.607480600 & -2.803740300 \\
& $(0.305573746)$ & $(0)$ & $(0)$ \\
2.5 & 1.049168281 & 5.756030567 & -2.878015283 \\
& $(0.251438545)$ & $(0)$ & $(0)$ \\
3 & 0.898580622 & 5.854025737 & -2.927012869 \\
& $(0.214123717)$ & $(0)$ & $(0)$ \\
\hline
\end{tabular}

() dual solution 
Figure 4 shows that nanoparticle volume fraction increases with the increasing in $\gamma$. Generally, it is noticed that the suction effect has a great impact on the concentration profile as it is shown in Figure 4. It is seen that the suction effect causes the nanoparticle volume fraction gradient on the surface. As a result, the magnitude of the reduced Sherwood number is expected to be increased.

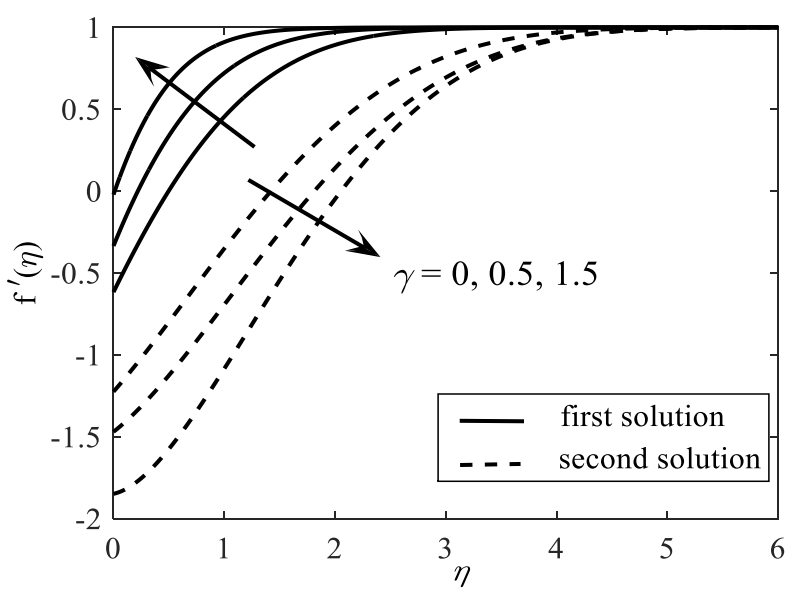

Fig. 2. The velocity profiles $f^{\prime}(\eta)$ for different values of $\gamma$ in shrinking case

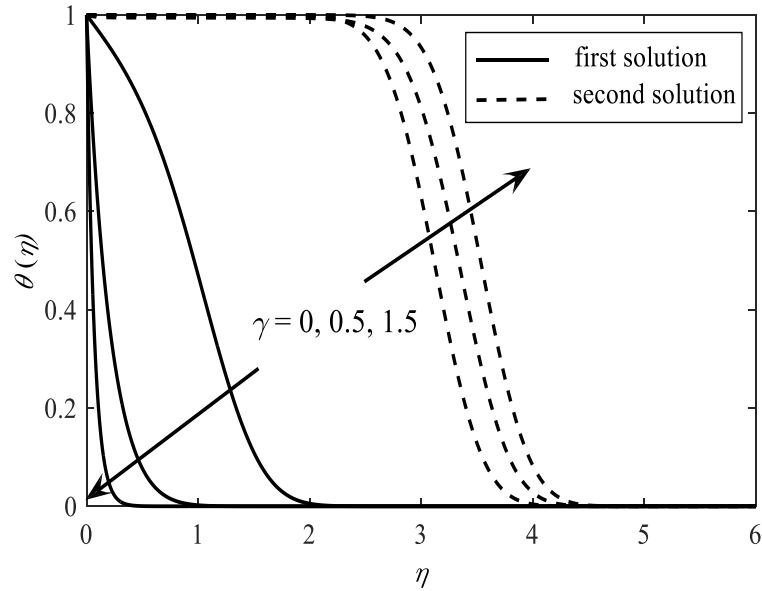

Fig. 3. The temperature profiles $\theta(\eta)$ for different values of $\gamma$ in shrinking case

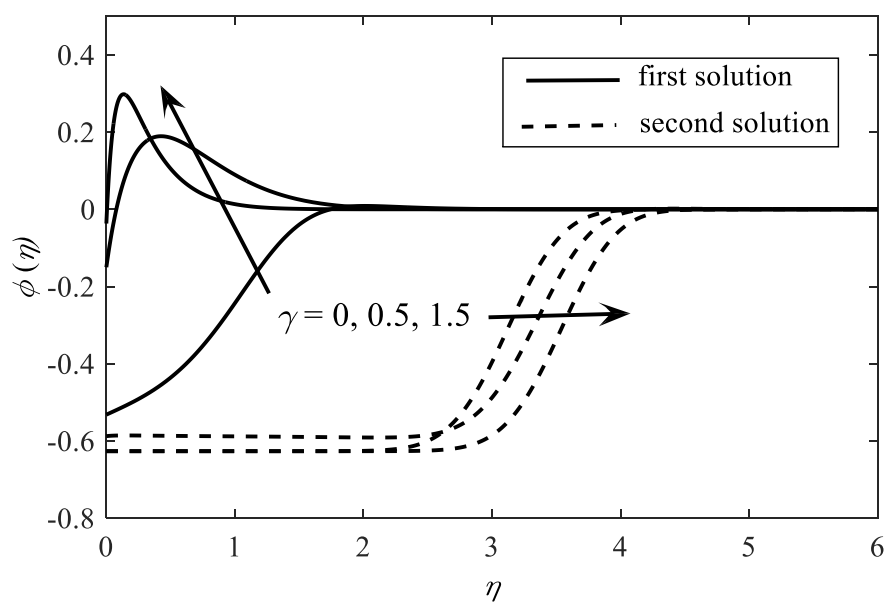

Fig. 4. The nanoparticle volume fraction profiles $\phi(\eta)$ for different values of $\gamma$ shrinking case

Figures 5-7 demonstrate the variation of $C f_{x} \operatorname{Re}_{x}^{1 / 2}, N u_{x} \operatorname{Re}_{x}^{-1 / 2}$ and $S h_{x} \operatorname{Re}_{x}^{-1 / 2}$ with $\varepsilon$ for different values of $\gamma$ in passive control when $\operatorname{Pr}=10, N_{b t}=2, N_{c}=0.5, L e=4, \lambda=0.2, S c=2, \delta=1$ and $r=1$. These figures indicate that the dual solutions exist in the shrinking region for a certain range of the stretching/shrinking parameter $\varepsilon$. The first solution meets the second solution at a particular point or specifically the critical value $\varepsilon$ is denoted by $\varepsilon_{c}$. It appears that, the solution domain increases with $\varepsilon_{c}$ which shifted to the left as the suction parameter $\gamma$ increases. Based on our findings, the critical values $\varepsilon$ for $\gamma=0,0.5$ and 1.5 are $\varepsilon_{c}=-2.239,-2.920$ and -4.820 , respectively. Thus, it is justified that the boundary layer separation has been delayed with the increment of $\gamma$.

From Figure 5, it seems that the values of $C f_{x} \operatorname{Re}_{x}^{1 / 2}$ increase as $\gamma$ increases for the first solution, while the opposite trend is shown for the second solution. This observation occurs due to the fact 
that as $\gamma$ increases, the wall shear stress decreases, the fluid velocity increases and as the result, the velocity gradient decreases at the surface, consistent with the graph presented in Figure 2 . On the other hand, Figure 6 points out that the heat transfer rate at the surface represented by $N u_{x} \operatorname{Re}_{x}^{-1 / 2}$ is enhanced due to the increasing suction effect for both solutions. Physically, this phenomenon occurs because of the decreasing thermal boundary layer thickness due to the suction effect, then it increases the temperature gradient on the surface and in turn it causes more fluid to move away from the boundary layer. This finding is consistent with the temperature profile $\theta(\eta)$ presented in Figure 3.

Figure 7 displays that the values of magnitude of $S h_{x} \mathrm{Re}_{x}^{-1 / 2}$ increase as $\gamma$ increases for the first solution. With the addition of the suction effect, the nanoparticle volume fraction boundary layer thickness is reduced, thereby increasing the nanoparticle volume fraction of fluid and as a result it increases the nanoparticle volume fraction gradient on the surface which is consistent with the nanoparticle volume fraction profile $\theta(\eta)$ illustrated in Figure 4. From Figures 2-3, it is noticed that the velocity gradient, temperature gradient, and nanoparticle concentration gradient increase with the reduction in momentum, thermal and concentration boundary layer thicknesses as $\gamma$ increases. It is worthy to highlight that the decrement of these boundary layers tends to enhance the skin friction coefficient, the heat transfer, and the mass transfer rate at the surface which consistent with the graph exhibited in Figures 5-7.

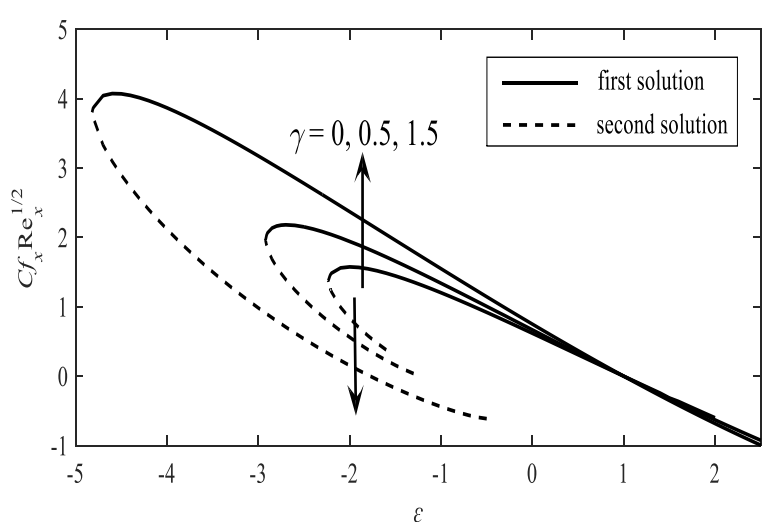

Fig. 5. Variation of $C f_{x} \operatorname{Re}_{x}^{1 / 2}$ with $\varepsilon$ for different values of $\gamma$

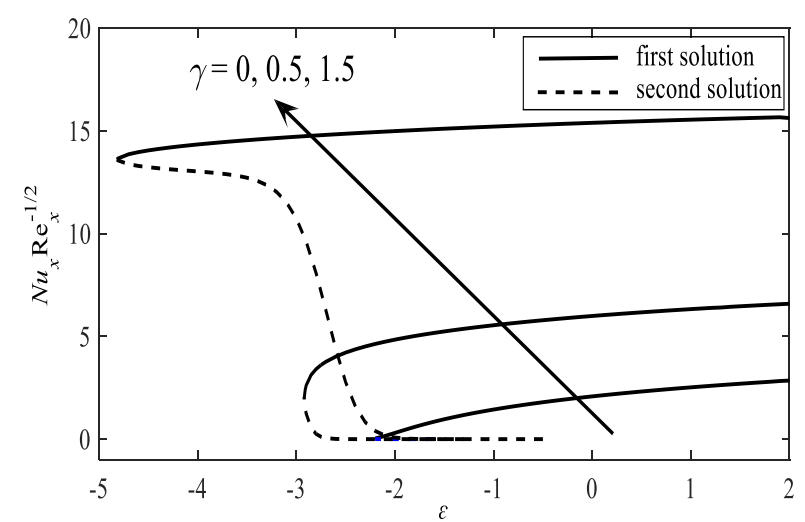

Fig. 6. Variation of $N u_{x} \operatorname{Re}_{x}^{-1 / 2}$ with $\varepsilon$ for different values of $\gamma$

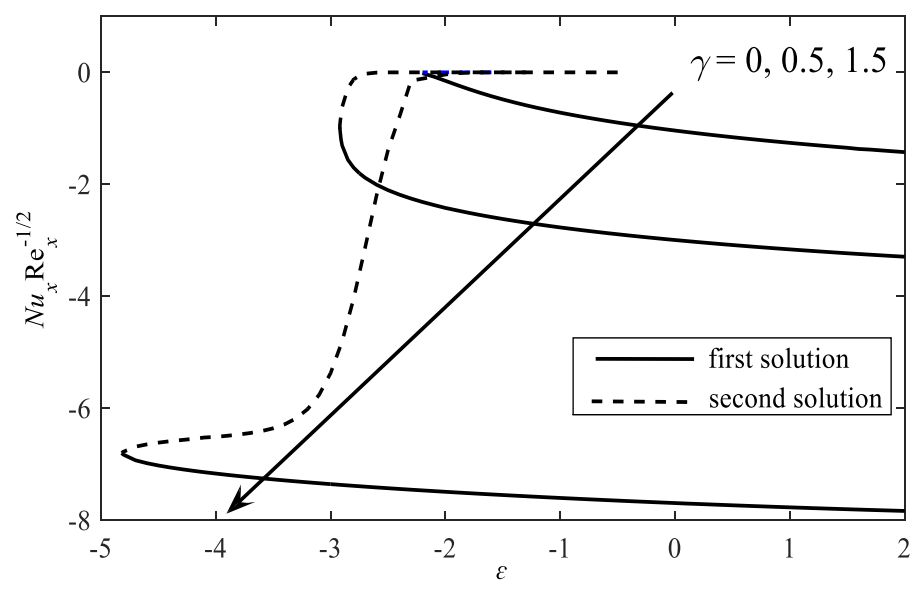

Fig. 7. Variation of the local Sherwood number $S h_{x} \operatorname{Re}_{x}^{-1 / 2}$ with $\varepsilon$ for different values of $\gamma$ 
The effects of the partial slip parameter $\delta$ on the velocity, temperature and nanoparticle volume fraction for passive control when $L e=4, \lambda=0.2, S c=2, r=1, \gamma=0.5, \operatorname{Pr}=10, N_{b t}=2, N_{c}=0.5$ and $\varepsilon=-2$ (shrinking) are exhibited in Figures $8-10$. In Figure 8 , when the values of $\delta$ increase, the fluid velocity for the first solution is increased, then heat is dispersed more quickly in the surrounding and as the consequence, the fluid temperature is reduced, as shown in Figure 9. This phenomenon occurs because of the increasing partial slip parameter has accelerated the fluid inside the boundary layer. From Figure 10, the temperature is found to be decreased with increasing in $\delta$ indicating that a shrinking sheet heat the boundary layer. Figure 10 displays that a similar trend is recognized for the nanoparticle volume fraction profile to that in Figure 9 for temperature profile. As partial slip parameter increases, nanoparticle volume fraction is depressed.

Similar to the suction effect on the domain of the solution, the critical value $\varepsilon$ moves to the left side as the slip parameter $\delta$ increases. Based on the numerical computation obtained, the critical values $\varepsilon$ are as follows for $\delta=0.5,1.5$ and 2.5 is $\varepsilon_{c}=-2.120,-3.780$ and -5.539 , respectively. We can say that the partial slip effect also widens the range of the existing dual solution and indirectly delays the separation of the boundary layer.

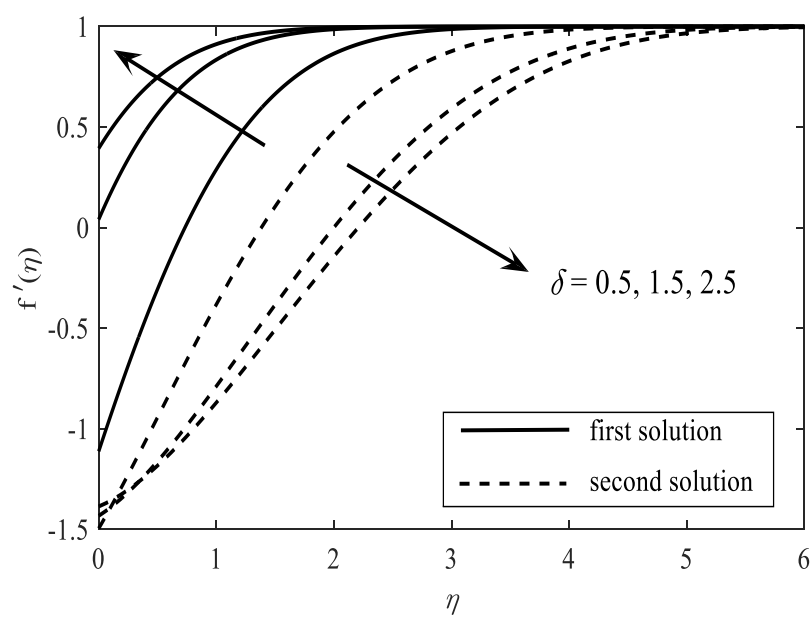

Fig. 8. The velocity profiles $f^{\prime}(\eta)$ for different values of $\delta$ in shrinking case

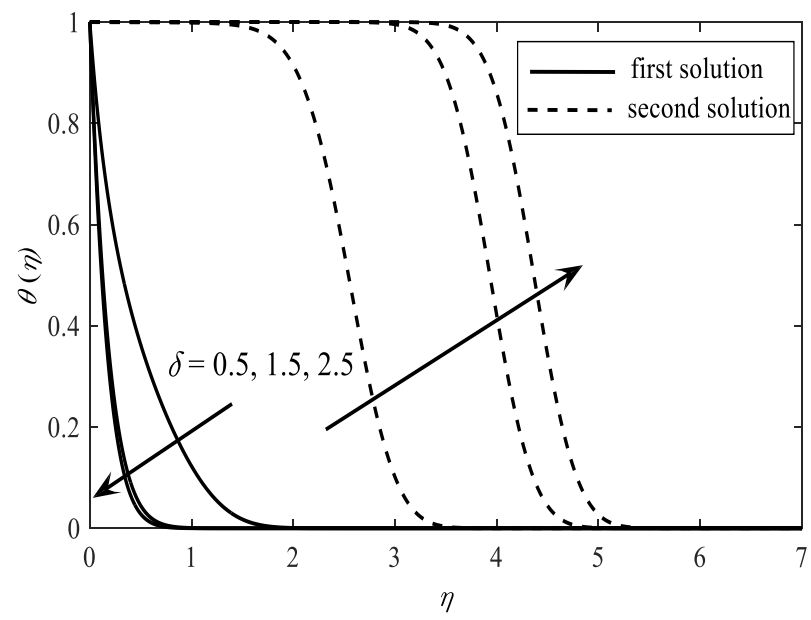

Fig. 9. The temperature profiles $\theta(\eta)$ for different values of $\delta$ in shrinking case

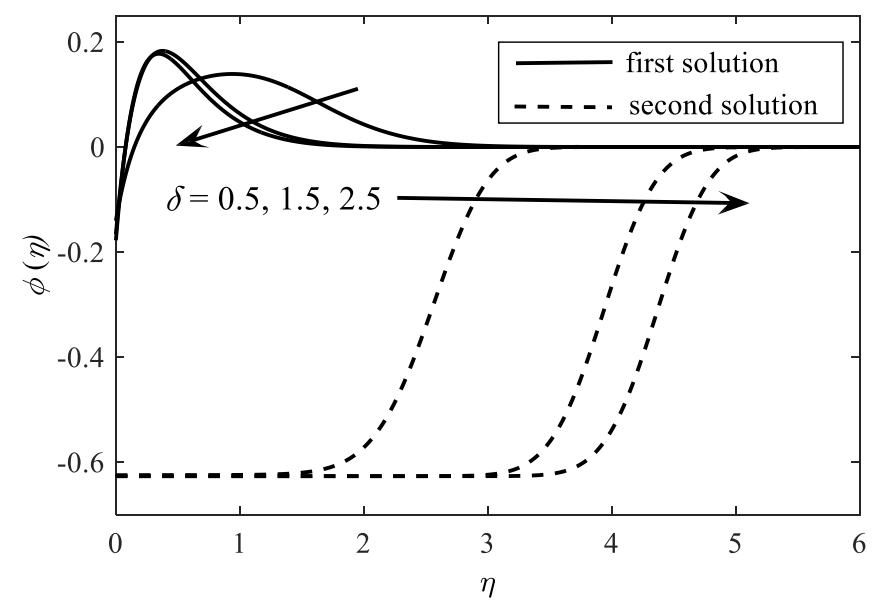

Fig. 10. The nanoparticle volume fraction profiles $\phi(\eta)$ for different values of $\delta$ in shrinking case 
Figures 11-13 exhibit the variation of $C f_{x} \operatorname{Re}_{x}^{1 / 2}, N u_{x} \operatorname{Re}_{x}^{-1 / 2}$ and $S h_{x} \operatorname{Re}_{x}^{-1 / 2}$ with $\varepsilon$ for different values of $\delta$ when $\operatorname{Pr}=10, N_{b t}=2, N_{c}=0.5, L e=4, \lambda=0.2, S c=2, r=1$ and $\gamma=0.5$ for passive control. In detail, Figure 11 shows the variation of the skin friction coefficient with $\varepsilon$ for different values of the partial slip parameter $\delta$. It is observed that the reduced skin friction coefficient $C f_{x} \operatorname{Re}_{x}^{1 / 2}$ increases when $\delta$ increases. The results also indicate that the skin friction coefficient is larger on the shrinking surface compared to that of the stretching surface. In Figure 12, the effects of $\delta$ on the reduced Nusselt number which represents the heat transfer rate are presented. It is noted that the rate of heat transfer is increasing as $\delta$ increases for the first solution. It is also revealed that the range of dual solution exists, also expands to the left as $\delta$ increase suggests that the partial slip effect widens the range of the dual solution. Also, it is observed that the heat transfer on the stretching surface is higher than the heat transfer on the shrinking surface as illustrated in Figure 12.

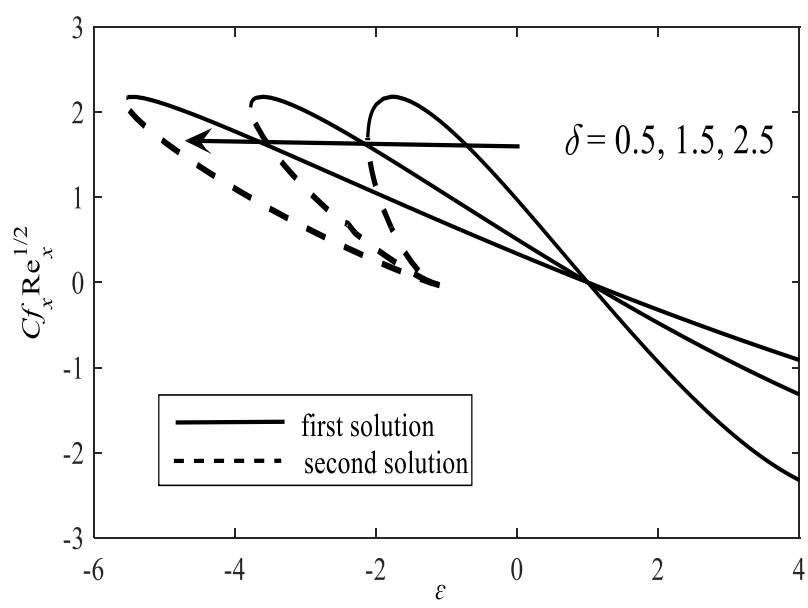

Fig. 11. Variation of $C f_{x} \operatorname{Re}_{x}^{1 / 2}$ with $\varepsilon$ for different values of $\delta$ in shrinking case

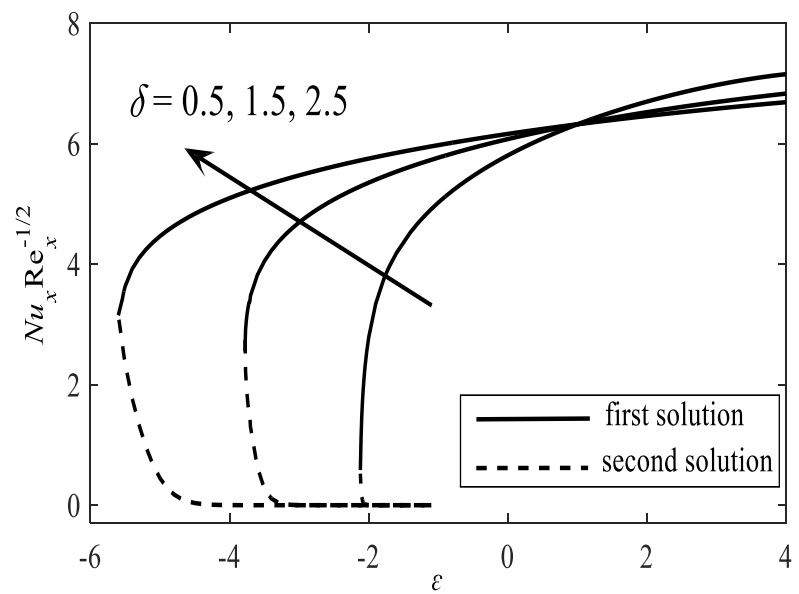

Fig. 12. Variation of $N u_{x} \mathrm{Re}_{x}^{-1 / 2}$ with $\varepsilon$ for different values of $\delta$ in shrinking case

Based on Figure 12, it is also expected that the values of $N u_{x} \operatorname{Re}_{x}^{-1 / 2}$ gradually increase and remain at a constant value as $\varepsilon$ increases. Referring to Figure 13 , it can be seen that the magnitude of the reduced Sherwood number $S h_{x} \mathrm{Re}_{x}^{-1 / 2}$ increases as $\delta$ increases for the first solution. From Figures 810 , the reduction in momentum, thermal and concentration boundary layers thicknesses with the increase in partial slip strength tend to enhance the skin friction coefficient, the reduced Nusselt number, and the reduced Sherwood number as displayed in Figures 11-13.

Finally, the velocity, temperature and nanoparticle volume fraction profiles shown in Figures 2-4, 8-9 and 10 fulfill the far field boundary conditions in Eqs. (16)-(18) asymptotically, which gives confidence to the numerical results of the present study and the existence of the dual solutions attained. 


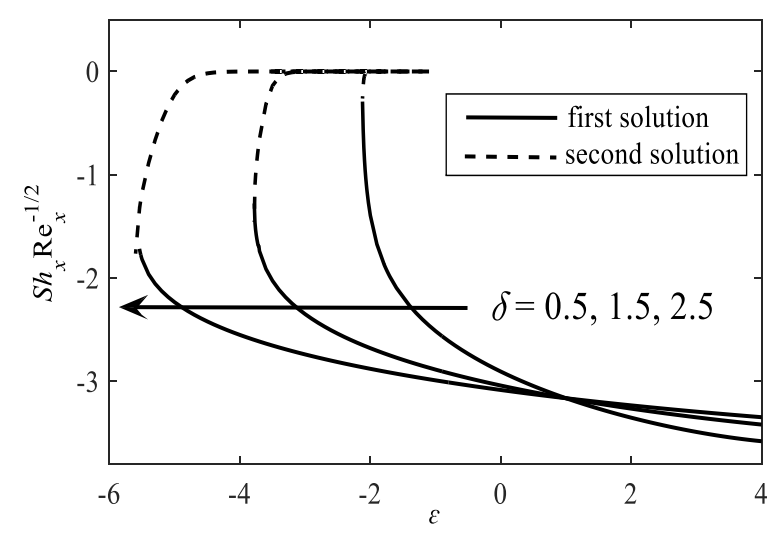

Fig. 13. Variation of the local Sherwood number $S h_{x} \mathrm{Re}_{x}^{-1 / 2}$ with $\varepsilon$ for different values of $\delta$

\section{Conclusions}

The problem of a two-dimensional steady stagnation point flow of an incompressible Williamson nanofluid is solved numerically on both the shrinking and stretching surfaces. This present study focuses only on the passive control on the wall mass flux. Both conditions of zero and nonzero normal fluxes are introduced at the surface while considering the effects of both Brownian motion and thermophoresis for validation and to obtain new numerical results. The numerical results are produced by converting the governing partial differential equations into a set of coupled nonlinear ordinary differential equations. Two main effects considered in this study namely, the partial slip parameter and the suction parameter. Numerical solution is obtained by using the boundary value problem solver bvp4c in MATLAB software. Furthermore, the impacts of partial slip parameter and the suction parameter over the skin friction coefficient, the reduced Nusselt number and the reduced Sherwood number are presented through tables and graphs. The main results of the present study are listed below:

I. Both velocity and nanoparticle volume fraction increase as the suction parameter increases while the temperature acts in the opposite manner.

II. The velocity increases as the partial slip parameter increases whereas temperature and nanoparticle volume fraction decrease.

III. The magnitude of the skin friction coefficient, the reduced Nusselt number and the reduced Sherwood number are notably increased for the first solution with the increasing suction parameter.

IV. An increase in partial slip parameter decreases the skin friction coefficient but the opposite is true in the reduced Nusselt number and the reduced Sherwood number.

V. The increment of the suction and partial slip effects has increase the range of dual solutions exist and indirectly delayed the boundary layer separation.

VI. The reduction in momentum, thermal and concentration boundary layers thicknesses with the increase in partial slip and suction impacts tend to enhance the skin friction coefficient, the reduced Nusselt number, and the reduced Sherwood number.

VII. Dual solutions exist up to a specific range of the stretching/shrinking parameters in the shrinking region.

VIII. The first solution is found to be stable and physically applicable but the second solution is not based on the literature for the similar problem presented by other researchers. 


\section{Acknowledgement}

The author would like to acknowledge the support from the Fundamental Research Grant Scheme (FRGS) under a grant number of FRGS/1/2018/STG06/UNIMAP/02/3 from the Ministry of Education Malaysia.

\section{References}

[1] Choi, S.U.S. "Enhancing thermal conductivity of fluids with Nanoparticles. Developments and applications of nonNewtonian flows." AJME, FED231/MD 66 (1995): 99-105.

[2] Buongiorno, J. "Convective Transport in Nanofluids." ASME J. Heat Tran. 128, no.3 (2006): 240-250. http://dx.doi.org/10.1115/1.2150834

[3] Wakif, Abderrahim, Ali Chamkha, Thirupathi Thumma, I.L. Animasaun, and Rachid Sehaqui. "Thermal radiation and surface roughness effects on the thermo-magneto-hydrodynamic stability of alumina-copper oxide hybrid nanofluids utilizing the generalized Buongiorno's nanofluid model." Journal of Thermal Analysis Calorimetry (2020) https://doi.org/10.1007/s10973-020-09488-z

[4] Sheri, Siva Reddy and Thirupathi Thumma. "Numerical study of heat transfer enhancement in MHD free convection flow over vertical plate utilizing nanofluids." Ain Shams Engineering Journal 9, no. 4 (2018): 1169-1180.

https://doi.org/10.1016/j.asej.2016.06.015

[5] Thumma, Thirupathi, S.R. Mishra, and M.D. Shamshuddin. "Effect of heat generation and viscous dissipation on MHD 3D Casson nanofluid flow past an impermeable stretching sheet." Numerical Heat Transfer and Fluid Flow. Lecture Notes in Mechanical Engineering (2019): 575-585. https://doi.org/10.1007/978-981-13-1903-7 66

[6] Rout, B.C., S.R. Mishra, and Thirupathi Thumma. "Effect of viscous dissipation on Cu-water and Cu-kerosene nanofluids of axisymmetric radiative squeezing flow." Heat transfer-Asian Research 48, no. 7 (2019): 3039-3054. https://doi.org/10.1002/htj.21529

[7] Khan, Masood, Hashim, and Abdul Hafeez. "A review on slip-flow and heat transfer performance of nanofluids from a permeable shrinking surface with thermal radiation: dual solutions." Chemical Engineering Science 173 (2017): 1 11.

https://doi.org/10.1016/i.ces.2017.07.024

[8] Ali, Hashim, Abdul Hafeez, Ali Saleh Alshomrani, and M. Khan. "Multiple physical aspects during the flow and heat transfer analysis of Carreau fluid with nanoparticles." Scientific Reports 8, no. 1 (2018): 1-14.

https://doi.org/10.1038/s41598-018-35462-9

[9] Hamid, A., Hashim, Abdul Hafeez, Masood Khan, A.S. Alshomrani, and Metib Alghamdi. "Heat transport features of magnetic water-graphene oxide nanofluid flow with thermal radiation: Stability Test." European Journal of Mechanics-B/Fluids 76 (2019): 434-441. https://doi.org/10.1016/j.euromechflu.2019.04.008

[10] Dero, Sumera, Azizah Mohd Rohni, and Azizan Saaban. "MHD Micropolar Nanofluid Flow over an Exponentially Stretching/Shrinking Surface: Triple Solutions." Journal of Advanced Research in Fluid Mechanics and Thermal Sciences 56, no. 2 (2019): 165-174.

[11] Ramachandra Prasad, V., A. Subba Rao, and O. Anwar Bég. "Flow and heat transfer of casson fluid from a horizontal circular cylinder with partial slip in non-darcy porous medium." J App/ Computat Math 2, no. 2 (2013). https://doi.org/10.4172/2168-9679.1000127

[12] Alkasasbeh, Hamzeh Taha. "Numerical solution of micropolar Casson fluid behaviour on steady MHD natural convective flow about a solid sphere." Journal of Advanced Research in Fluid Mechanics and Thermal Sciences 50, no. 1 (2018): 55-66.

[13] Nadeem, S., S.T. Hussain, and Changhoon Lee. "Flow of a Williamson fluid over a stretching sheet." Brazilian Journal of Chemical Engineering 30, no. 3 (2013): 619-625.

http://dx.doi.org/10.1590/S0104-66322013000300019

[14] Williamson, R.V. "The Flow of Pseudoplastic Materials." Ind. Eng. Chem. 21, no. 11 (1929): 1108-1111. https://doi.org/10.1021/ie50239a035

[15] Nadeem, S. and S.T. Hussain. "Flow and heat transfer analysis of Williamson nanofluid." Applied Nanoscience 4 (2014): 1005-1012. https://doi.org/10.1007/s13204-013-0282-1

[16] Halim, N.A., S. Sivasankaran, and N.F.M. Noor. "Active and passive controls of the Williamson stagnation nanofluid flow over a stretching/shrinking surface." Neural Computing and Application 28 (2017): 1023-1033.

https://doi.org/10.1007/s00521-016-2380-y 
[17] Kuznetsov, A. V., and D. A. Nield. "The Cheng-Minkowycz problem for natural convective boundary layer flow in a porous medium saturated by a nanofluid: a revised model." International Journal of Heat and Mass Transfer 65 (2013): 682-685. https://doi.org/10.1016/i.ijheatmasstransfer.2013.06.054

[18] Hamid, Aamir, Hashim, Masood Khan, and Abdul Hafeez. "Unsteady stagnation-point flow of Williamson fluid generated by stretching/shrinking sheet with Ohmic heating." International Journal of Heat and Mass Transfer 126 (2018): 933-940. https://doi.org/10.1016/j.ijheatmasstransfer.2018.05.076

[19] Uwanta, I.J. and M.M. Hamza. "Effect of suction/injection on unsteady hydromagnetic convective flow of reactive viscous fluid between vertical porous plates with thermal diffusion." International Scholarly Research Notices 2014 (2014) https://doi.org/10.1155/2014/980270

[20] Thumma, Thirupathi, A. Chamkha, and Siva Reddy Sheri. "MHD natural convective flow of nanofluids past stationary and moving inclined porous plate considering temperature and concentration gradients with suction." International Journal of Numerical Methods for Heat and Fluid Flow 27, no. 8 (2017): 1765-1794. https://doi.org/10.1108/HFF-03-2016-0090

[21] Andersson, H.I. "Slip flow past a stretching surface." Acta Mech. 158, no. 1 (2002): 121-125. https://doi.org/10.1007/BF01463174

[22] Prasannakumara, B.C., M.R. Krishnamurthy, B.J. Gireesha, and Rama S.R. Gorla. "Effect of multiple slips and thermal radiation on mhd flow of Jeffery nanofluid with heat transfer." Journal of Nanofluids 5 (2016): 1-12. https://doi.org/10.1166/jon.2016.1198

[23] Shidlovskiy. V.P. Introduction to the dynamics of rarefied gases. American Elsevier Publishing Company Inc., New York, 1967.

[24] Yoshimura, Ann, and Robert K. Prud'homme. "Wall slip corrections for Couette and parallel disk viscometers." Journal of Rheology 32, no. 1 (1988): 53-67. https://doi.org/10.1122/1.549963

[25] Alblawi, Adel, Muhammad Yousaf Malik, Sohail Nadeem, and Nadeem Abbas. "Buongiorno's nanofluid model over a curved exponentially stretching surface." Processes 7 (2019): 665 https://doi.org/10.3390/pr7100665

[26] Mahian, Omid, Lioua Kolsi, Mohammad Amani, Patrice Estellé, Goodarz Ahmadi, Clement Kleinstreuer, Jeffrey S. Marshall et al. "Recent advances in modeling and simulation of nanofluid flows-Part I: Fundamentals and theory." Physics reports 790 (2019): 1-48. https://doi.org/10.1016/i.physrep.2018.11.004

[27] Thumma, Thirupathi, and S.R. Mishra. "Effect of viscous dissipation and Joule heating on magnetohydrodynamic Jeffery nanofluid flow with and without multi slip boundary conditions." J. Nanofluids 7, no. 3 (2018): 516-526. https://doi.org/10.1166/jon.2018.1469

[28] Thumma, Thirupathi, O. Anwar Bég, and A.Kadir. "Numerical study of heat source/sink effects on dissipative magnetic nanofluid flow from a non-linear inclined stretching/shrinking sheet." Journal of Molecular Liquids 232 (2017): 159-173. https://doi.org/10.1016/j.molliq.2017.02.032

[29] Bég, O.A., T. Thumma, and S.R. Sheri. "Finite element computation of magnetohydrodynamic nanofluid convection from an oscillating inclined plate with radiative flux, heat source and variable temperature effects." Proc. IMechE Part N: Journal of Nanomaterials, Nanoengineering and Nanosystems 231, no.4 (2017): 179-194. https://doi.org/10.1177/2397791417731452

[30] Thumma, Thirupathi, and S.R. Mishra. "Effect of non-uniform heat source/sink, viscous and Joule dissipation on 3D Eyring - Powell nanofluid flow over a stretching sheet." Journal of Computational Design and Engineering 7, no. 0 (2020): 1-15. https://doi.org/10.1093/icde/qwaa034

[31] Fang, T., Shanshan Yao, Ji Zhang, and Abdul Aziz.m. "Viscous flow over a shrinking sheet with a second order slip flow model." Commun. Nonlinear Sci. Numer. Simul. 15, no. 7 (2010): 1831-1842. https://doi.org/10.1016/i.cnsns.2009.07.017

[32] Hale, N. P. "A sixth-order extension to the matlab bvp4c software of j. kierzenka and I. shampine." Department of Mathematics, Imperial College London (2006).

[33] Kierzenka, Jacek. and Lawrence F. Shampine. "A BVP solver based on residual control and the MALTAB PSE." ACM Transactions on Mathematical Software 27, no. 3 (2001): 299-316. https://doi.org/10.1145/502800.502801 
[34] Merkin, J.H. "Mixed convection boundary layer flow on a vertical surface in a saturated porous medium." Journal of Engineering Mathematics 14, no. 4 (1980): 301-313.

https://doi.org/10.1007/BF00052913

[35] Weidman, P.D., D.G. Kubitschek, and A.M.J. Davis. "The effect of transpiration on self-similar boundary layer flow over moving surfaces." International Journal of Engineering Science 44, no. 11/12 (2006): 730-737. https://doi.org/10.1016/j.ijengsci.2006.04.005

[36] Harris, S.D., D.B. Ingham, and I. Pop. "Mixed convection boundary-layer flow near the stagnation point on a vertical surface in a porous medium: Brinkman model with slip." Transport in Porous Media 77 (2009): 267-285. https://doi.org/10.1007/s11242-008-9309-6

[37] Adnan, Nurul Shahirah Mohd, Norihan Md Arifin, Norfifah Bachok, and Fadzilah Md Ali. "Stability analysis of MHD flow and heat transfer passing a permeable exponentially shrinking sheet with partial slip and thermal radiation." CFD Letters 11, no.12 (2019): 34-42.

[38] Sharma, R., A. Ishak, R. Nazar, and I. Pop. "Boundary layer flow and heat transfer over a permeable exponentially shrinking sheet in the presence of thermal radiation and partial slip." Journal of Applied Fluid Mechanics 7, no. 1 (2014): 125-134.

https://doi.org/10.36884/jafm.7.01.19489 